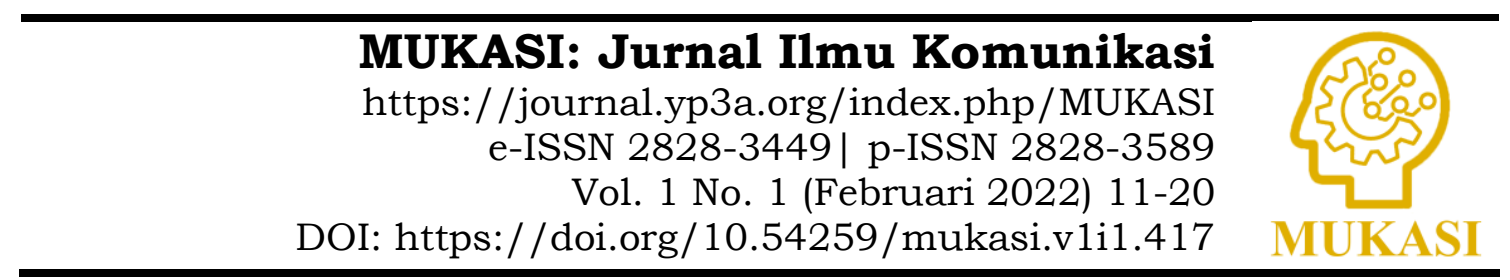

\title{
Analisis Agenda Setting Pemberitaan MotoGP Mandalika Pada RRI Mataram
}

\author{
Hayatun Sofian', Yulanda Trisula SY ${ }^{2 *}$, Sandi Justitia Putra ${ }^{3}$, Lalu Ahmad Rahmat ${ }^{4}$, \\ I Made Putra Suryantara ${ }^{5}$ \\ 1,2,3,4,5 Program Studi Ilmu Komunikasi, Fakultas Ilmu Sosial dan Ilmu Politik, Universitas 45 Mataram, \\ Kota Mataram, Indonesia \\ ${ }^{1}$ hayatunsofian@gmail.com, ${ }^{2 *}$ yulandatrisula@gmail.com, ${ }^{3}$ sandijustitiaputra@gmail.com, \\ ${ }^{4}$ laluahmadrahmad@gmail.com, 5imadeputrasuryantara@gmail.com
}

\begin{abstract}
This research has an important urgency because the public will tend to pay attention to the things that are the priority of mass media coverage. The media setting agenda can relate the possible effects of influencing public opinion or opinion so that it does not only pay attention to priority news but also learns how important the way the mass media prioritizes news topics is. Formulate the problem in this study is "How is the agenda setting of the Mandalika MotoGP News RRI Mataram?" The research approach used by the researcher is qualitative. Determination of the main issues and other supporting news through a long process that is discussed in the agenda setting meeting. The negative and positive sides of the MotoGP event will be published in news bulletins so that reporters will be assigned to the field to find sources. The selection of sources is adjusted to the topic of the news/coverage. Resource persons are selected based on the competence of the position, the suitability of the substance of the problem and the ability to act as a decision maker. After the news topics are determined, the next job is to do the coverage. Coverage is done to dig up data and facts, to be processed into news. This is where the reporter plays a very important role. The reporter's tenacity and tenacity are tested, because coverage is not always easy because sources are often hard to find. Therefore the reporter must make a coverage plan. The coverage plan must include the following: What or who will be the object/subject of the coverage, Where will the coverage be carried out, What information will be obtained (Questions should be prepared in the form of open-ended questions) What is the angle of the news?, Who Will the right sources be found to strengthen the news?.The researcher concludes that Agenda Setting is a forum for discussing the main topic or issue based on considerations such as the issue being discussed by the community How significant the issue is for the community or listeners The issue can also be considered from whether other media carry it Agenda Setting has a very important and strategic role in concocting and framing news, especially about the MotoGP world motorcycle racing event at the Mandalika Circuit, Central Lombok. Even from the agenda setting, synergistic communication was created by reporters, editors and deputy editors who were very harmonious even though there were debates in determining the main issues to be presented in the RRI Mataram news bulletin. RRI Mataram as a Public Broadcasting Institution in MotoGP reporting is independent and neutral so that the information does not favor certain parties but is more in the public interest.
\end{abstract}

Keywords: Agenda Setting, News, MotoGP 


\begin{abstract}
Abstrak
Penelitian ini memiliki urgensi yang penting karena publik akan cenderung memperhatikan hal-hal yang menjadi prioritas pemberitaan media massa. Agenda setting media dapat menghubungkan kemungkinan terjadinya efek mempengaruhi pendapat atau opini publik sehingga tidak hanya memperhatikan terhadap berita yang menjadi prioritas tetapi juga mempelajari seberapa besar arti penting dari cara media massa memprioritaskan topik berita tersebut. Rumuskan masalah dalam penelitian ini adalah "Bagaimana agenda setting Pemberitaan MotoGP Mandalika RRI Mataram?" Pendekatan Penelitian yang digunakan peneliti yakni kualitatif. Penetapan isu utama dan news supporting lainnya melalui proses panjang yakni dibahas dalam rapat agenda setting. Sisi negatif dan positif dari gelaran MotoGP itu akan dimuat dalam buletin berita sehingga reporter akan ditugaskan kelapangan untuk mencari narasumber. Penentuan narasumber disesuaikan dengan topik berita/liputan. Narasumber dipilih berdasarkan kompetensi jabatan, kesesuaian substansi permasalahan dan kemampuan bertindak sebagai decision maker. Setelah topik-topik berita ditentukan maka pekerjaan berikutkanya adalah melakukan peliputan. Liputan dilakukan untuk menggali data dan fakta, untuk diolah menjadi berita. Disinilah reporter memegang peranan yang sangat penting. Kegigihan dan keuletan reporter diuji, sebab liputan tidak selalu mudah karena narasumber sering kali sulit ditemui. Oleh karen itu reporter harus membuat rencana liputan. Rencana liputan itu harus mencakup hal-hal berikut: $\square$ Apa atau siapa yang akan menjadi objek/subjek liputan ? Dimana liputan akan dilakukan $\square$ Informasi apa saja yang akan didapatkan (Pertanyaan-pertanyaan seyogyangnya disiapkan dalam bentuk pertanyaan terbuka) Bagaimana angle beritanya?, Siapakah narasumber yang tepat akan ditemui untuk memperkuat berita?. Peneliti mengambil kesimpulan bahwa Agenda Setting merupakan wadah dalam membahas topik atau isu utama yang didasarkan pada pertimbangan-pertimbangan seperti isu yang sedang diperbincangkan masyarakat Seberapa signifikan isu itu bagi masyarakat atau pendengar Isu juga bisa dipertimbangkan dari apakah media-media lain mengangkut hal itu Selain itu juga Agenda Setting memiliki peran yang sangat penting dan strategis dalam meramu dan membingkai sebuah berita khususnya tentang perhelatan balap motor dunia MotoGP di Sirkuit Mandalika Lombok Tengah. Bahkan dari agenda setting itu tercipta komunikasi sinergis oleh reporter, editor dan wakil redaksi yang sangat harmonis meski terdapat perdebatan dalam menentukan isu utama yang akan disuguhkan dalam bulletin berita RRI Mataram. RRI Mataram sebagai Lembaga Penyiaran Publik pada pemberitaan MotoGP bersikap independen dan netral sehingga informasinya tidak memihak kepada pihak tertentu tetapi lebih kepada kepentingan publik.
\end{abstract}

Kata kunci: Agenda Setting, Pemberitaan, MotoGP

\title{
PENDAHULUAN
}

Indonesia resmi masuk dalam daftar kalender penyelenggaraan MotoGP 2021, dan sudah tercantum dalam situs resmi gelaran balap motor dunia tersebut. Dalam situs resmi MotoGP, Indonesia yang akan menggunakan Sirkuit Mandalika, di Kawasan Ekonomi Khusus (KEK) Mandalika, Praya, Lombok Tengah, dimana menjadi tuan rumah di seri ke-15. Dalam memastikan kesiapan sirkuit Mandalika, Perwakilan Dorna Sports selaku pemegang hak komersial MotoGP belum lama ini telah mengunjungi Sirkuit Mandalika, Lombok, Nusa Tenggara Barat (NTB), pada hari Rabu (7/4/21) yang dihadiri langsung oleh FIM Safety Officer Franco Uncini, Perwakilan Race Direction LorisCapirossi, dan Managing Director Dorna Sports, Carlos Ezpeleta. 
Bidang Pemberitaan Radio Republik Indonesia (RRI) Mataram memiliki tugas dalam mengisi media pemberitaan dengan berita-berita yang layak atau informasi-informasi yang terbaru yang dimana dibutuhkan oleh masyarakat. Dimana berita atau informasi yang diciptakan dapat menarik para pendengar atau audience untuk dapat tertarik dengan apa yang disampaikan. Selain itu berita yang akan disampaikan juga harus memenuhi standar dan harus bermanfaat.

Pemberitaan RRI Mataram memiliki kepedulian yang tinggi dalam menyuguhkan gelaran MotoGP Indonesia yang terpusat di Sirkuit Mandalika Lombok Tengah. Informasi dari berbagai linipun disuguhkan mulai dari proses pembebasan lahan, pembangunan sirkuit dan juga fasilitas pendampingnya seperti hotel, homestay serta bandara. Hasil framing menyuguhkan informasi yang berimbang sehingga tidak menimbulkan kegaduhan bagi masyarakat pendengar RRI. Oleh karena itu diperlukan proses yang baik agar isu-isu yang memiliki hard news dapat tersusun dengan baik sehingga tersaji informasi sesuai yang ingin dicapai dalam memenuhi kebutuhan informasi masyarakat. Ketua dewan redaksi dalam hal ini mendorong para reporter untuk menggali secara mendalam seluruh proses yang ada bagi terselenggaranya gelaran MotoGP di Sirkuit Mandalika. Bahkan kesiapan kabupaten dan kota dalam menyambut gelaran MotoGP juga tidak luput untuk di informasikan ke masyarakat. Seperti halnya kota Mataram, Lombok Barat, Lombok Utara dan Lombok Timur. Kesiapan dari berbagai sisi dari kabupaten dan kota ini penting disampaikan mulai dari kesiapan hotel, homstay, transportasi dan lainnya sebab gelaran MotoGP akan mendatangkan banyak orang dari berbagai belahan dunia.

Reporter diarahkan untuk mengggali informasi dari pemangku kebijakan di pemerintah provinsi, kabupaten dan kota, pengelola hotel dan restoran, organda serta lainnya dalam menghadapi MotoGP di Sirkuit Mandalika Lombok Tengah. Kota Mataram sebagai ibu kota provinsi Nusa Tenggara Barat, bahkan tidak ingin ketinggalan dalam menghadapi pelaksanaan MotoGP. Berbagai persiapan ditempuh dalam menerima limpahan dari pelaksanaan MotoGP di Lombok Tengah. Kesiapan hotel, restoran, rumah makan, pusat oleh-oleh terus dilakukan. Pemerintah Kota Mataram melakukan yang terbaik bersinergi dengan pelaku usaha mikro kecil dan menengah (UMKM), manajemen hotel dan restoran serta pengelola rumah makan dan pengelola pusat oleh-oleh. Banyaknya pengunjung ataupun penonton yang akan hadir menyaksikan balap motor dunia ini akan berdampak besar terhadap perekonomian masyarakat sehingga kabupaten kota lainnya di NTB melakukan berbagai langkah strategis bagi kesuksesan MotoGP.

Oleh karena itu, penelitian ini memiliki urgensi yang penting karena publik akan cenderung memperhatikan hal-hal yang menjadi prioritas pemberitaan media massa. Agenda setting media dapat menghubungkan kemungkinan terjadinya efek mempengaruhi pendapat atau opini publik sehingga tidak hanya memperhatikan terhadap berita yang menjadi prioritas tetapi juga mempelajari seberapa besar arti penting dari cara media massa memprioritaskan topik berita tersebut. Berdasarkan latar belakang masalah yang dikemukakan diatas, maka rumuskan masalah dalam penelitian ini adalah "Bagaimana agenda setting Pemberitaan MotoGP Mandalika RRI Mataram?"

\section{TINJAUAN PUSTAKA}

Agenda Setting sangat penting dalam menciptakan public awareness (kesadaran masyarakat) dengan menekankan sebuah isu yang dianggap paling penting untuk dilihat, didengar, dibaca, dan dipercaya di media massa. Definisi agenda setting menurut Syukur Kholil dan Samsudin A. Rahim dalam Kholil (2007:36) mengemukakan bahwa: "Peran media massa yang mempunyai kekuatan untuk 
mempengaruhi pendapat dan perilaku masyarakat dengan menentukan agenda terhadap masalah yang dipandang penting."

Sementara itu, Agenda Setting menurut Maxwell E. McCombs dan Donald L. Shaw dalam Nuruddin (2007:195) menjelaskan bahwa media massa memiliki kemampuan untuk mentransfer hal yang menonjol yang dimiliki sebuah berita dari agenda berita mereka kepada agenda publik. Pada saatnya, media massa mampu membuat apa yang penting menurutnya, menjadi penting pula bagi masyarakat.

Berdasarkan dua definisi diatas maka dapat disimpulkan bahwa agenda setting membicarakan tentang peran besar media massa dalam menentukan agenda. Masyarakat menjadi terbiasakan dengan berita-berita yang disampaikan media, sehingga menjadi bahan pembicaraan dalam pergaulan sehari-hari. Berita atau informasi yang disampaikan media tersebut bukan saja hanya sebagai ilmu atau pengetahuan bagi masyarakat, tetapi bahkan bisa mengubah gaya hidup, perilaku, ataupun sikap masyarakat. Oleh sebab itu, agenda setting memiliki peranan yang sangat baik dalam memformulasikan isu ataupun agenda publik yang akan dibingkai menjadi sebuah berita yang menarik untuk pendengar RRI. Sehingga beberapa proses yang ada dalam agenda setting harus dilaksanakan dengan sebaik mungkin bagi tersedianya informasi ataupun berita yang aktual, terpercaya dan memenuhi keinginan publik.

Dua asumsi dasar yang paling mendasari penelitian tentang penentuan agenda setting adalah : 1) masyarakat pers dan mass media tidak mencerminkan kenyataan, mereka menyaring dan membentuk isu, 2) konsentrasi media massa hanya pada beberapa masalah masyarakat untuk ditayangkan sebagai isu-isu yang lebih penting daripada isuisu lain (Littlejohn \& Foss, 2009: 416).

Adapun agenda yang dapat ditentukan oleh media massa adalah: a) Apa yang harus dipikirkan oleh masyarakat; b) Menentukan fakta yang harus dipercayai oleh masyarakat; c) Menentukan penyelesaian terhadap suatu masalah ; d) Menentukan tumpuan perhatian terhadap suatu masalah; e) Menentukan apa yang perlu diketahui dan dilakukan masyarakat (Kholil, 2007: 36).

Untuk itulah, agenda setting dalam media massa mengarahkan "apa yang harus dipikirkan" oleh publik melalui penonjolan isu-isu (priming), dan membingkai (framing) pesan-pesan media. Kekuasaan media bergantung pada faktor-faktor, seperti kredibilitas media terhadap isu-isu tertentu pada saat-saat tertentu, tingkat pertentangan bukti yang dirasakan oleh individu anggota masyarakat, tingkat dimana individu berbagi nilai media pada waktu-waktu tertentu, dan kebutuhan masyarakat Littlejohn dan Foss, (Teori, h. 417).

Sedangkan Radio merupakan media auditif (hanya bisa didengar), tetapi murah, merakyat dan bisa dibawa atau didengarkan dimana saja. Radio berfungsi sebagai media ekspresi, komunikasi, informasi, pendidikan, dan hiburan. Radio memiliki kekuatan terbesar sebagai media imajinasi, sebab sebagai media yang buta, radio menstimulasi begitu banyak suara, dan berupaya menvisualisasikan suara penyiar ataupun informasi faktual melalui telinga pendengarnya (Masduki, 2001:9). Setiap stasiun radio harus memiliki program acara dengan tujuan mempertahankan pendengar dan menarik pendengar baru serta mengundang pemasang iklan. Program acara memiliki beberapa jenis salah satunya program acara berita. Program acara berita merupakan sebuah program yang tidak akan pernah dilupakan untuk didengarkan karena program ini berisikan berbagai informasi yang sangat dibutuhkan oleh seluruh masyarakat luas.

Menurut George Fox Mott (dalam Iskandar 2003:22) mengatakan, berita adalah laporan yang tepat waktu mengenai fakta yang akurat atau opini yang memiliki daya tarik atau hal penting atau kedua-duanya bagi masyarakat luas. Berita diartikan sebagai laporan atas opini atau peristiwa yang penting bagi sejumlah khalayak ramai. Berita yang besar 
adalah liputan opini atau peristiwa, yang sangat dibutuhkan pula bagi banyak orang. Siaran Berita merupakan siaran yang kini sedang diminati dan bersaing ketat baik dimedia televisi maupun radio, untuk menarik perhatian masyarakat dengan cara merubah pola sajian siaran dalam berbagai bentuk sehingga menarik perhatian dan tidak monoton.

Menurut Masduki (2001:9), jika dalam media cetak pengertian berita adalah peristiwa yang diulang, maka dalam radio berita adalah peristiwa yang dikomunikasikan kepada pendengar pada saat yang bersamaan dengan peristiwanya.

\section{METODE}

Pendekatan Penelitian yang digunakan peneliti yakni kualitatif atau disebut juga data naratif, adalah data dalam penelitian yang menjelaskan suatu fenomena berdasarkan halhal yang umumnya tidak dapat dihitung. Menurut Sugiyono (2015) kualitatif adalah data yang berbentuk kata, skema, dan gambar. Data kualitatif penelitian ini berupa nama dan alamat obyek penelitian.Berdasarkan definisi diatas maka peneliti akan melakukan atau akan menjelaskan fenomena yang ada dilapangan, kemudian peneliti akan menyusunnya dalam bentuk bahasa ataupun dalam bentuk gambar yang ditemukan dalam dokumentasi peneliti.

Sesuai dengan judul dan studi kasus, lokasi penelitian peneliti yaitu di LPP RRI Mataram. Peneliti memilih RRI Mataram karena berdasarkan pengamatan di lapangan dalam menggunakan media siaran khususnya pada proses Agenda Setting belum menunjukkan upaya maksimal untuk mencapai tujuan yakni suguhan pemberitaan yang akurat, tepat dan berimbang kepada masyarakat terkait MotoGP.Yang dimaksud subyek penelitian, adalah orang, tempat, atau benda yang diamati sebagai sasaran ( Kamus Bahasa Indonesia, 1989: 862). Adapun subyek penelitian dalam tulisan ini, di RRI Mataram yang meliputi Kepala Bidang Pemberitaan, Desk Editor dan Reporter.

Sumber data yang digunakan dalam penelitian ini yaitu : 1. Data Primer yang menurut Hasan (2002: 82) data primer ialah data yang diperoleh atau dikumpulkan langsung di lapangan oleh orang yang melakukan penelitian atau yang bersangkutan yang memerlukannya. Data primer di dapat dari sumber informan yaitu individu atau perseorangan seperti hasil wawancara yang dilakukan oleh peneliti. Data primer ini antara lain; Catatan hasil wawancara dan hasil observasi lapangan. Sumber data primer dalam penelitian ini adalah Kepala Bidang, Desk Editor dan Reporter. Sedangkan data sekunder adalah data yang diperoleh atau dikumpulkan oleh orang yang melakukan penelitian dari sumber-sumber yang telah ada Hasan (2002: 58). Sumber data sekunder diperoleh melalui dokumentasi dan studi kepustakaan dengan bantuan media internet serta catatan lapangan. Sumber data sekunder merupakan sumber data tidak langsung yang mampu memberikan data tambahan serta penguatan terhadap data penelitian.

Teknik analisis data adalah proses pengumpulan data secara sistematisuntukmempermudah peneliti dalam memperoleh kesimpulan. Analisis data menurutBogdan dalam Sugiyono yaitu proses mencari dan menyusun secara sistematikdata yang diperoleh dari hasil wawancara, catatan lapangan, dan bahan-bahan lainsehingga dapat mudah dipahami dan temuannya dapat diinformasikan kepadaorang lain.Analisis data kualitatif bersifat induktif, yaitu analisis berdasarkandata yang diperoleh.

Menurut Miles \& Huberman (1992: 16) analisis terdiri dari tiga alur kegiatanyang terjadi secara bersamaan yaitu: reduksi data, penyajian data, penarikankesimpulan/verifikasi. Mengenai ketiga alur tersebut secara lebih lengkapnyaadalah sebagai berikut: 
1. Reduksi Data

Reduksi data diartikan sebagai proses pemilihan, pemusatan perhatian padapenyederhanaan, pengabstrakan, dan transformasi data kasar yang muncul daricatatan-catatan tertulis di lapangan. Reduksi data merupakansuatu bentuk analisis yang menajamkan, menggolongkan, mengarahkan,membuang yang tidak perlu, dan mengorganisasi data dengan cara sedemikianrupa hingga kesimpulankesimpulan finalnya dapat ditarik dan diverifikasi.Peneliti dalam hal ini akan melakukan pemilahan terhadap data mana saja yang relevan digunakan untuk memperkuat laporan peneletian utamanya dari hasil wawancara dan observasi.

Selain itu juga membuat rangkuman, memilih hal-hal pokok, memfokuskan pada hal-hal penting, serta membuang yang dianggap tidak perlu. Dengan demikian, data yang direduksi akan memberikan gambaran yang lebih spesisifk dan mempermudah peneliti melakukan pengumpulan data selanjutnya serta mencari data tambahan jika diperlukan.

2. Penyajian Data

Miles \& Huberman membatasi suatu penyajian sebagai sekumpulaninformasi tersusun yang memberi kemungkinan adanya penarikan kesimpulandan pengambilan tindakan. Mereka meyakini bahwa penyajian-penyajian yanglebih baik merupakan suatu cara yang utama bagi analisis kualitatif yang valid,yang meliputi: berbagai jenis matrik, grafik, jaringan dan bagan. Semuanyadirancangguna menggabungkan informasi yang tersusun dalam suatu bentuk yang padu dan mudah diraih.

Peneliti dalam hal ini melakukan penyajian data dalam bentuk uraian naratif, bagan, hubungan antar kategori dan lain sejenisnya. Penyajian data dalam bentukbentuk tersebut akan memudahkan peneliti memahami apa yang terjadi dan merencanakan kerja penelitian selanjutnya. Pada tahap penyajian data, peneliti berusaha menyusun data yang relevan untuk menghasilkan informasi yang dapat disimpulkan dan memiliki makna tertentu. Prosesnya dapat dilakukan dengan cara menampilkan dan membuat hubungan antar fenomena untuk memaknai apa yang sebenarnya terjadi dan apa yang perlu ditindaklanjuti untuk mencapai tujuan penelitian.

3. Menarik Kesimpulan

Penarikan kesimpulan menurut Miles \& Huberman, hanyalah sebagian dari satu kegiatan dari konfigurasi yang utuh. Kesimpulan-kesimpulan juga diverifikasi selama penelitian berlangsung. Verifikasi itu mungkin sesingkat pemikiran kembali yang melintas dalam pikiran peneliti, suatu tinjauan ulang pada catatan-catatan lapangan, atau mungkin menjadi begitu seksama dan menghabiskan tenaga dengan peninjauan kembali serta tukar pikiran di antara teman sejawat untuk mengembangkan kesepakatan inter subjektif atau juga upaya-upaya yang luas untuk menempatkan salinan suatu temuan dalam seperangkat data yang lain. Kesimpulan akhir tidak hanya terjadi pada waktu proses pengumpulan data saja, akan tetapi perlu diverifikasi agar benar-benar dapat dipertanggung jawabkan.

Penarikan kesimpulan dilakukan dengan jalan membandingkan kesesuaian pernyataan informan dengan makna yang terkandung dalam masalah peneliti secara konseptual. Secara skematisproses analisis data menggunakan model analisis data interaktif 


\section{HASIL DAN PEMBAHASAN}

Berdasarkan hasil penelitian, maka peneliti melakukan pembahasan terkait hasil temuan di lapangan. Pada tahap ini peneliti melakukan pembahasan berdasarkan fokus penelitian yang telah diterapkan, serta data dari hasil penelitian yang diperoleh selama penelitian berlangsung. MotoGP menjadi isu yang ditonjolkan dan diramu secara mendalam melalui rapat agenda setting di bidang pemberitaan RRI Mataram. Isu MotoGP ini dibahas secara gamblang dalam menemukan point-point penting yang nantinya di jadikan bahan liputan dilapangan dan selanjutnya di kemas dalam sebuah laporan berita. Pada penelitian ini peneliti menemukan adanya silang pendapat antara reporter dan redaktur maupun desk editor yang memiliki tujuan yang sama yakni menjadikan MotoGP sebagai isu berita yang harus dipoles, dikemas dan diramu sebaik mungkin bagi kepentingan publik dan NTB.

Bahkan peneliti juga menemukan adanya komunikasi satu arah bak gayung bersambut sebab terjadi interaksi yang beriringan yang hajatannya adalah mencari benang merah atau persoalan, manfaat dan dampaknya dari keberadaan MotoGP yang dihelat di Sirkuit MotoGP Mandalika Lombok Tengah. Berdasarkan hasil wawancara dan observasi pasca agenda setting, maka dapat diketahui bahwa "AnalisisAgenda Setting Pemberitaan MotoGP Mandalika Pada RRI Mataram" merupakan marwah dari berita yang keluar dan disuguhkan oleh RRI Mataram bagi masyarakat di Nusa Tenggara Barat.

Agenda setting menempatkan reporter dengan media massa sebagai kekuatan yang mampu membentuk opini publik dengan sekaligus melaksanakan pengemasan pesan (framing strategis) sehingga tersuguhkan informasi yang optimal. Dengan agenda setting maka akan terformulasikan buletin berita yang benar-benar dibutuhkan oleh publik seperti halnya MotoGP sangat ditunggu oleh masyarakat. Pengemasan berita tentang MotoGP dari berbagai sisi akan memberikan dampak besar bagi masyarakat karena MotoGP ini merupakan yang pertama di Indonesia yang diselenggarakan di Sirkuit Mandalika Lombok Tengah. Momentum bersejarah ini membuat RRI Mataram melalui bidang pemberitaan berbuat seoptimal mungkin untuk bisa menyuguhkan informasi mengingat MotoGP adalah isu yang sangat strategis dari berbagai sisi.

Keputusan di dalam agenda setting dalam hal ini berita seputar MotoGP diputuskan dalam rapat redaksi, dan pada perbincangan lain bisa disebut rapat agenda setting. Rapat agenda setting dimulai pagi hari setelah seluruh reporter tiba di kantor setiap hari mulai Senin hingga Jumat pada pukul 08.00 sampai 08.30 pada hari Senin hingga Kamis. Sedangkan hari Jumat dilaksanakan pada pukul 07.30 hingga 08.30 Wita. Rapat dimulai dan dipimpin oleh Kepala Bidang Pemberitaan selaku Wakil Pemimpin Redaksi. Adapun Pemimpin Redaksi di RRI Mataram adalah Kepala Stasiun RRI Mataram. Pemimpin Redaksi sesekali hadir untuk memberikan arah isu apa yang paling mengemuka belakangan ini.

Penetapan isu utama ditetapkan melalui rapat agenda setting yang melibatkan seluruh reporter, kadesk, produser dan pengarah acara. Pemilihan suatu isu didasarkan pada pertimbangan-pertimbangan seperti apakah isu itu sedang diperbincangkan masyarakat? Seberapa signifikan isu itu bagi masyarakat atau pendengar? Isu juga bisa dipertimbangkan dari apakah media-media lain mengangkat hal itu?

Ketika media-media mengangkat isu tersebut berarti bahwa isu itu menarik dan banyak diperbincangkan. Namun ketika isu itu yang dipertimbangkan berasal dari media lain maka penting dipertimbangkan apakah ada hal baru yang akan diangkat? Ini penting agar kita tidak sekedar mengulang apa yang telah disiarkan oleh media lain. Redaksi bisa memunculkan suatu isu untuk diangkat sebagai berita berdasarkan kajian atas isu 
yang berkembang atau isu sebelumnya yang terlupakan, atau berdasarkan calender event.

Selama rapat agenda setting, peserta wajib memiliki atau menyampaikan isu atau rencana liputan. Apabila dalam rapat agenda setting belum muncul isu atau rencana liputan yang dijadikan topik utama, pimpinan rapat agenda setting akan mengarahkan kebijakan liputan baik yang mendukung berita yang akan dijadikan topik utama, atau liputan berdasarkan interes sebagai unsur variasi berita.

Penetapan isu utama dan news supporting lainnya, tak terkecuali MotoGP juga melalui proses panjang yakni dibahas dalam rapat agenda setting. Sisi negative dan positif dari gelaran MotoGP itu akan dimuat dalam buletin berita sehingga reporter akan ditugaskan kelapangan untuk mencari narasumber. Penentuan narasumber disesuaikan dengan topik berita/liputan. Narasumber dipilih berdasarkan kompetisi jabatan, kesesuaian substansi permasalahan dan kemampuan bertindak sebagai decision maker.

Setelah topik-topik berita ditentukan maka pekerjaan berikutkanya adalah melakukan peliputan. Liputan dilakukan untuk menggali data dan fakta, untuk diolah menjadi berita. Disinilah reporter memegang peranan yang sangat penting. Kegigihan dan keuletan reporter diuji, sebab liputan tidak selalu mudah karena narasumber sering kali sulit ditemui. Oleh karen itu reporter harus membuat rencana liputan. Rencana liputan itu harus mencakup hal-hal berikut:

$>$ Apa atau siapa yang akan menjadi objek/subjek liputan?

$>$ Dimana liputan akan dilakukan?

$>$ Informasi apa saja yang akan didapatkan? (Pertanyaan-pertanyaan seyogyangnya disiapkan dalam bentuk pertanyaan terbuka)

$>$ Bagaimana angle beritanya?

$>$ Siapakah narasumber yang tepat akan ditemui untuk memperkuat berita?

Reporter wajib memiliki alasan terhadap setiap pilihan objek/subjek liputan sehingga dapat diproduksi sebagai berita yang layak siar dan memiliki news value (nilai berita) yang tinggi. Setelah reporter mengumpulkan bahan berita berupa data dan fakta, langkah berikutnya adalah menulis berita. Reporter dalam hal ini membuat berita sesuai dengan hasil liputan yang diperoleh dilapangan. Hasil peliputan dilapangan seperti halnya MotoGP akan dibuat sedemikian rupa oleh reporter sesuai dengan fakta dan data. Sebelum disiarkan, naskah berita hasil liputan reporter akan dikoreksi atau dilakukan editing terlebih dahulu oleh editor. Koreksi tersebut dilakukan untuk mengetahui apakah sebuah berita memenuhi kriteria layak siar ataukah tidak. Insert/sisipan berita juga harus didengar ulang. Selain untuk menentukan kelayakan siarnya juga untuk mengetahui apakah insert berita itu memenuhi syarat clean and clear (jernih dan jelas). Sisipan berita merupakan statement atau pernyataan penting dari sumber berita yang berfungsi untuk memperkuat atau menegaskan berita.

Setiap berita yang akan disiarkan haruslah memenuhi kelayakan siar. Sebuah berita dinilai layak siar jika memenuhi hal sebagai berikut:

1. Berorientasi kepentingan publik

2. Memiliki news value

3. Timlines

4. Berita disajikan dengan memenuhi standar yakni:

a) Akurat

b) Berimbang

c) Sesuai dengan etika jurnalistik dan P3SPS (Pedoman Perilaku Penyiaran dan Standar Program Siaran)

5. Kualitas insert jernih dan jelas. 
Setelah berita ditetapkan laik siar, barulah berita tersebut dapat disiarkan sesuai jam siar berita yang sudah ditetapkan. Meskipun demikian, tidak berarti bahwa tugas jurnalistik atau editor selesai begitu berita disiarkan. Sebaliknya, harus dilakukan evaluasi atas berita yang telah disiarkan.

Di RRI, evaluasi atas berita-berita yang telah disiarkan dilakukan pada kesempatan rapat agenda setting besok paginya. Evaluasi dilakukan untuk perbaikan pengembangan kegiatan liputan, dan penulisan naskah berita selanjutnya. Evaluasi bermanfaat untuk memperbaiki kesalahan yang telah dibuat, supaya tidak terulang kembali. Bahkan dengan evaluasi ini maka akan dapat diketahui kelebihan maupun kekurangan dari informasi atau berita yang disuguhkan kepada publik, yang berkenaan dengan MotoGP. Wakil redaksi dalam hal ini akan meminta para reporter untuk tidak cepat puas dengan berita yang telah dibuat tapi semakin gigih dan giat untuk mencari sudut pandang dari MotoGP ini sehingga informasi-informasi yang akan disuguhkan melalui bulletin berita akan benar-benar memenuhi keinginan masyarakat.

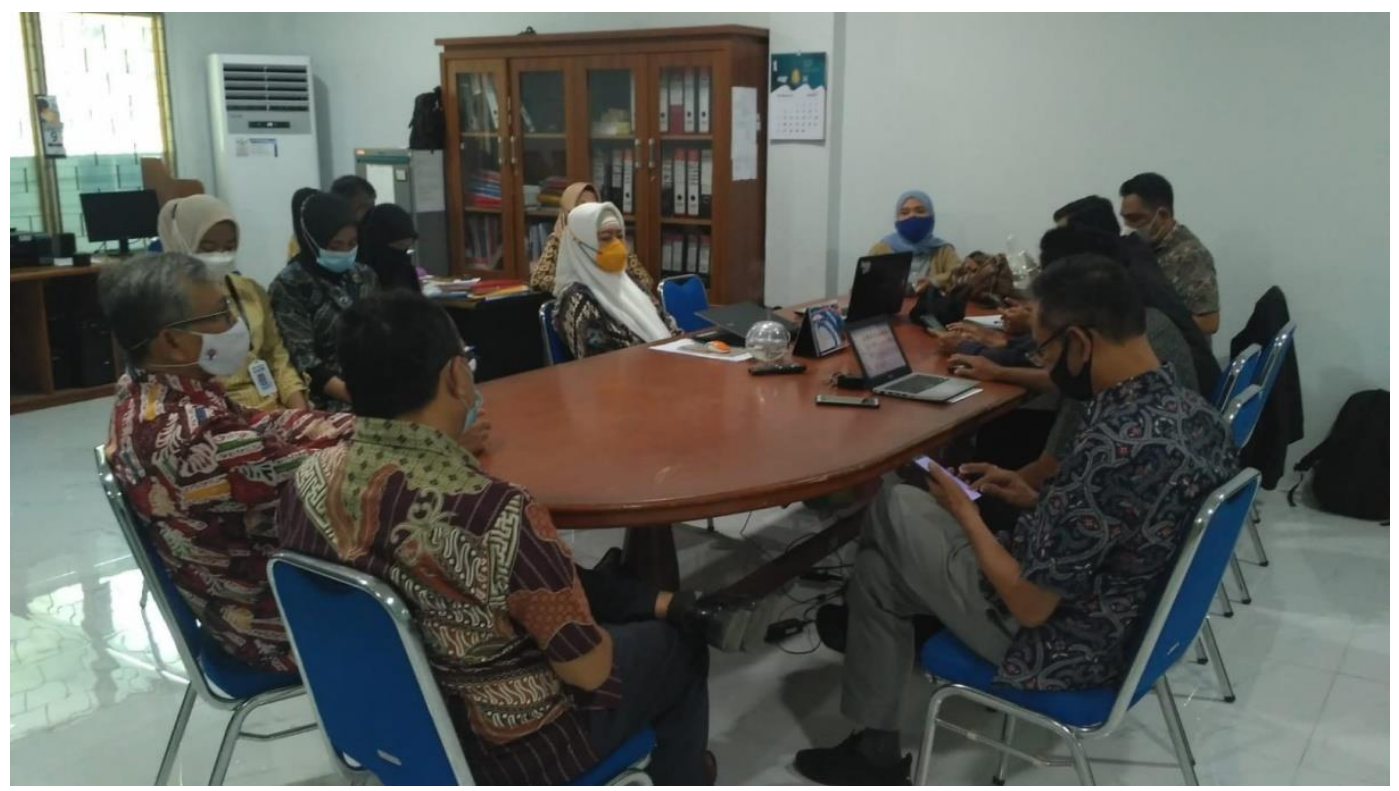

Sumber : Redaksi RRI Mataram

Gambar 1. Dokumentasi Rapat Agenda Setting Bidang Pemberitaan RRI Mataram

\section{PENUTUP}

Peneliti mengambil kesimpulan bahwa Agenda Settin merupakan wadah dalam membahas topik atau isu utama yang didasarkan pada pertimbangan-pertimbangan seperti isu yang sedang diperbincangkan masyarakat? Seberapa signifikan isu itu bagi masyarakat atau pendengar? Isu juga bisa dipertimbangkan dari apakah media-media lain mengangkut hal itu? Selain itu juga Agenda Setting memiliki peran yang sangat penting dan strategis dalam meramu dan membingkai sebuah berita khususnya tentang perhelatan balap motor dunia MotoGP di Sirkuit Mandalika Lombok Tengah.

Bahkan dari agenda setting itu tercipta komunikasi sinergis oleh reporter, editor dan wakil redaksi yang sangat harmonis meski terdapat perdebatan dalam menentukan isu utama yang akan disuguhkan dalam bulletin berita RRI Mataram. RRI Mataram sebagai Lembaga Penyiaran Publik pada pemberitaan MotoGP bersikap independen dan 
netral sehingga informasinya tidak memihak kepada pihak tertentu tetapi lebih kepada kepentingan publik.

\section{UCAPAN TERIMA KASIH}

Peneliti mengucapkan terima kasih kepada Yayasan Pendidikan Penelitian Pengabdian Algero yang telah berkenan menerbitkan karya penelitian in dan seluruh civitas akademik Universitas 45 Mataram atas dukungannya sehingga peneliti dapat menyelesaikan penyusunan karya ilmiah ini.

\section{DAFTAR PUSTAKA}

Hasan, M. Iqbal. (2002). Pokok-Pokok Materi Metodologi Penelitian dan Aplikasinya. Penerbit Ghalia Indonesia : Jakarta

Iskandar, Dudi Sabil \& Lestari, Rini. (2016). Mitos Jurnalisme. Yogyakarta: Penerbit ANDI.

Kholil, S.. (2007), Komunikasi Islami. Bandung: Citapustaka Media

Littlejohn, Stephen W \& Karen A. Foss.2009. Teori Komunikasi, edisi 9. Jakarta: Salemba Humanika

Masduki. 2001. Jurnalistik Radio: Menata Profesionalisme Reporter \& Penyiar Radio. Jakarta: Penebar Swadaya.

Miles dan Huberman. 1992. Analisis data Kualitatif. (diterjemahkan Ole: Tjetjep Rohedi Rosidi).

Jakarta: Universitas Indonesia.

Nuruddin. (2007), Pengantar Komunikasi Massa. Jakarta: Raja Grafindo Persada.

Sugiyono. (2007). Metode Penelitian Pendekatan Kuantitatif. 